\title{
Coupling mitochondrial respiratory chain to cell death: an essential role of mitochondrial complex I in the interferon- $\beta$ and retinoic acid-induced cancer cell death
}

\author{
G Huang ${ }^{1}, Y$ Chen $^{1}, \mathrm{H} \mathrm{Lu}^{1}$ and $\mathrm{X} \mathrm{Cao}^{*, 1}$
}

Combination of retinoic acids (RAs) and interferons (IFNs) has synergistic apoptotic effects and is used in cancer treatment. However, the underlying mechanisms remain unknown. Here, we demonstrate that mitochondrial respiratory chain (MRC) plays an essential role in the IFN- $\beta /$ RA-induced cancer cell death. We found that IFN- $\beta /$ RA upregulates the expression of MRC complex subunits. Mitochondrial-nuclear translocation of these subunits was not observed, but overproduction of reactive oxygen species (ROS), which causes loss of mitochondrial function, was detected upon IFN- $\beta$ /RA treatment. Knockdown of GRIM-19 (gene associated with retinoid-interferon-induced mortality-19) and NDUFS3 (NADH dehydrogenase (ubiquinone) Fe-S protein 3), two subunits of MRC complex I, by siRNA in two cancer cell lines conferred resistance to IFN- $\beta$ /RA-induced apoptosis and reduced ROS production. In parallel, expression of late genes induced by IFN- $\beta$ /RA that are directly involved in growth inhibition and cell death was also repressed in the knockdown cells. Our data suggest that the MRC regulates IFN- $\beta /$ RA-induced cell death by modulating ROS production and late gene expression.

Cell Death and Differentiation (2007) 14, 327-337. doi:10.1038/sj.cdd.4402004; published online 7 July 2006

Interferons (IFNs) play leading roles in the host defense against viruses, bacteria, and parasites. ${ }^{1}$ IFNs are also important negative growth factors that inhibit cell proliferation and induce apoptosis. ${ }^{2}$ Three major classes of IFNs, including IFN- $\alpha$, IFN- $\beta$, and IFN- $\gamma$, have been identified. ${ }^{3}$ Retinoic acids (RAs) are natural and synthetic derivatives of Vitamin A. Alltrans-retinoic acid and 9-cis-RA are active metabolites that bind and activate the nuclear receptors, all-trans-RA receptors (RARs) and retinoid X receptors (RXRs), and control expression of various genes. ${ }^{4,5}$ RAs inhibit proliferation and induce differentiation of cancer cells. ${ }^{6,7}$ Interestingly, RA and IFN potentiate each other to induce biological responses. Various combinations of RAs and IFNs have demonstrated synergistic effects by inhibiting proliferation and inducing differentiation, as well as apoptotic activity in cancer cell lines and in human hematologic and solid tumor models. ${ }^{8,9}$ However, the molecular basis of their effects is poorly understood.

GRIM-19 (genes associated with retinoid-IFN-induced mortality-19) was identified as an IFN- $\beta$ - and RA-induced gene with proapoptotic nature in the breast cancer cell lines. ${ }^{10}$ GRIM-19 was initially implicated as a nuclear protein, and its precise role in the IFN- $\beta$ - and RA-induced tumor cell death was not clear. ${ }^{10}$ Subsequently, the bovine GRIM-19 homolog was found to copurify with mitochondrial NADH:ubiquinone oxidoreductase (complex I) in the heart. ${ }^{11}$ GRIM-19 was also identified as a negative regulator of signal transducer and activator of transcription (Stat)3. ${ }^{12,13}$ To reveal its physiological role, we generated GRIM-19-deficient mice by gene targeting. ${ }^{14}$ Although the deletion of GRIM-19 causes

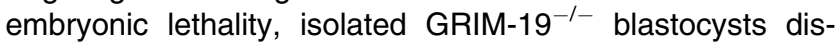
played abnormal mitochondrial structure and morphology. Consistent with this finding, we further demonstrated that GRIM-19 is localized in the mitochondria, associates with mitochondrial complex I, and plays essential roles in the assembly and enzymatic activity of complex I. ${ }^{14}$ Based on its primary function in mitochondria, GRIM-19 has been recently suggested to be re-named as NADH dehydrogenase (ubiquinone) 1 alpha subcomplex 13 (NDUFA13) by HUGO Gene Nomenclature Committee (HGNC).

Mitochondria play many roles in cells. They generate ATP by oxidative phosphorylation (OXPHOS) via the mitochondrial respiratory chain (MRC) consisting of five multisubunit complexes (complexes I-V), which are encoded either by mitochondrial or nuclear DNA. ${ }^{15-18}$ Mitochondria also play a pivotal role in apoptosis induced by a variety of extra- and intracellular stresses that leads to the release of potentially toxic proteins, such as cytochrome $c$, and subsequent caspase activation. ${ }^{19}$ To what extent its functions in 'life' and 'death' are related is still unclear. The finding that GRIM-19 is

\footnotetext{
${ }^{1}$ Signal Transduction Laboratory, Institute of Molecular and Cell Biology, Singapore, Republic of Singapore

*Corresponding author: X Cao, Signal Transduction Laboratory, Institute of Molecular and Cell Biology, 61 Biopolis Drive, Proteos Building, Singapore 138673, Republic of Singapore. Tel: +65-65869657; Fax: +65-67791117; E-mail: mcbcaoxm@ imcb.a-star.edu.sg

Keywords: mitochondrial respiratory chain; cell death; interferon- $\beta$ and retinoic acid

Abbreviations: IFNs, interferons; RA, all-trans-retinoic acid; GRIM, gene associated with retinoid-interferon-induced mortality; MRC, mitochondrial respiratory chain; OXPHOS, oxidative phosphorylation; AIF, apoptosis-inducing factor; FBS, fetal bovine serum; FITC, fluorescein isothiocyanate; ROS, reactive oxygen species; PI, propidium iodide; DAPI, 4',6-diamidino-2-phenylindole; PDTC, pyrrolidinedithiocarbamate; SOD, superoxide dismutase; $\Delta \Psi_{\mathrm{m}}$, transmembrane potential; TRAIL, TNFrelated apoptosis-inducing ligand; tTGase II, tissue transglutaminase II; IRF-1, interferon regulatory factor 1; Stat, signal transducer and activator of transcription Received 22.2.06; revised 17.5.06; accepted 29.5.06; Edited by M Piacentini; published online 07.7.06
} 
a complex I subunit raises a question of whether complex I, or the whole MRC in general, is involved and required for IFN/RA-induced cancer cell death. Our studies reported here indicate that IFN/RA-triggered cell death depends on the MRC, and therefore links normal MRC function to the apoptosis induced by IFN/RA treatment.

\section{Results}

IFN- $\beta$ /RA upregulates expression of various MRC subunits. Complex $\mathrm{I}$ is the largest complex in the MRC containing at least 46 subunits. ${ }^{20,21}$ it has been shown previously that IFN- $\beta /$ RA treatment increases the mRNA level of GRIM-19 in human breast carcinoma cell lines. ${ }^{10}$ In this study, we investigated whether IFN- $\beta$ /RA treatment can also stimulate expression of other MRC subunits in these cancer cell lines. We chose certain subunits encoded by the nucleus from complex I-V based on the antibody availability. Figure 1a shows that three subunits of complex I (GRIM-19, NDUFS3, and NDUFS5) were upregulated strongly and two (NUDFB6 and NDUFA9) increased slightly after treatment with IFN- $\beta /$ RA in MCF-7 cells. In addition, expression of subunits UQCRFS1, an iron-sulfur protein from complex III, COX II and COX IV from complex IV, and ATPI from complex
V were also elevated by IFN- $\beta$ /RA. In contrast, SDHA, a flavoprotein from complex II, which exhibited relatively high expression in the untreated cells, was not obviously enhanced after the treatment. A similar expression pattern of these individual subunits was also observed in HeLa cells. More importantly, the synergistic upregulation of these subunits was dependent on the combination of IFN- $\beta$ and $\mathrm{RA}$, as IFN- $\beta$ or RA alone had no inducing effect in most cases (Figure 1b). As controls, tubulin and actin were unchanged upon stimulation. These results indicate that the combination of IFN- $\beta$ and RA synergistically upregulates the expression of certain subunits of MRC complexes I, III, $\mathrm{IV}$, and $\mathrm{V}$ in the cancer cell lines.

To test whether the MRC subunits are upregulated at the transcriptional level, we performed real-time RT-PCR to quantify the mRNA amount of both GRIM-19 and NDUFS3 at different time points after the initiation of IFN- $\beta /$ RA stimulation. The results showed that their mRNA levels also increased by the treatment (Figure 1c).

IFN- $\beta$ /RA induces cell death via a mitochondrialmediated pathway. Next, the effects of IFN/RA on cell growth and death were examined. IFN- $\beta$ or RA alone reduced the cell number slightly $(<15 \%)$, whereas a combination of the two drugs resulted in a drastic decrease
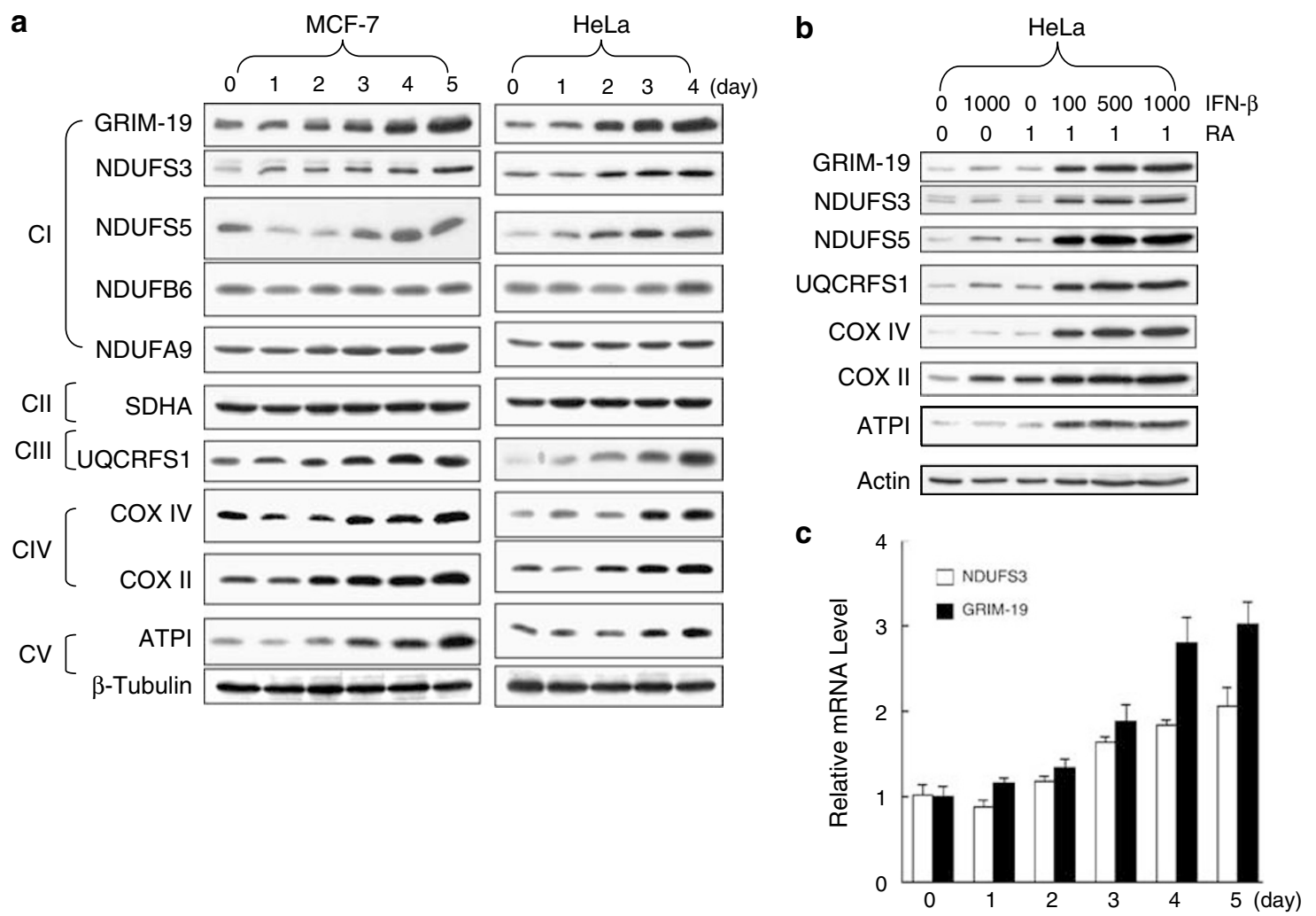

Figure 1 IFN- $\beta /$ RA combination upregulates MRC complex subunits. (a) MRC complex subunits upregulated by IFN- $\beta /$ RA in MCF-7 and HeLa cells. Cells were treated with $1500 \mathrm{U} / \mathrm{ml}$ of IFN- $\beta$ and $2 \mu \mathrm{M}$ of RA for different times as indicated. Cells were then harvested and lysed with RIPA buffer. Equal amounts of proteins were separated by SDS-PAGE and subjected to Western blot analysis using antibodies as indicated. Cl-CV indicate complexes I-V. The blot was reprobed with $\beta$-tubulin as a loading control. (b) Synergistic induction of complex subunits by a combination of IFN- $\beta$ and RA. HeLa cells were untreated or treated with different doses of IFN- $\beta$ (U/ml) and $1 \mu \mathrm{M}$ of RA as indicated for 5 days. Cells were harvested and the complex subunits were analyzed as described above. (c) GRIM-19 and NDUFS3 were upregulated at the transcriptional level. HeLa cells were treated as in (a). RNA was extracted at different time points as indicated. mRNA levels of GRIM-19 and NDUFS3 were quantified by real-time RT-PCR using GAPDH as an internal control 


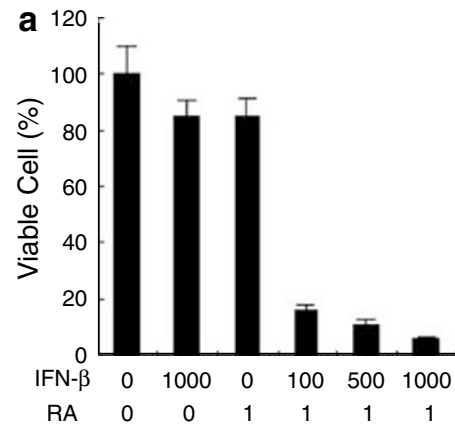

d

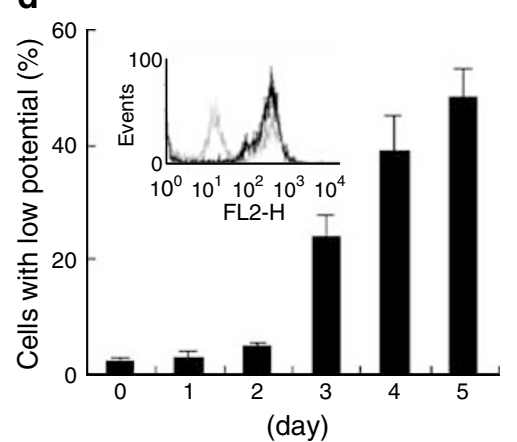

(day)

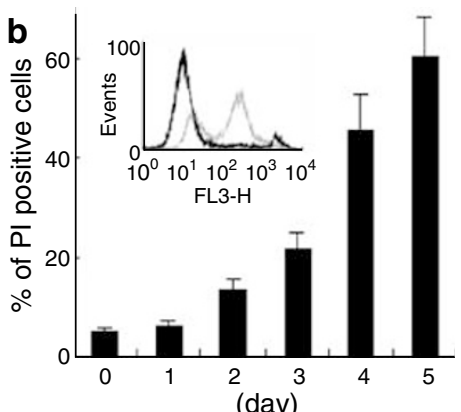

e

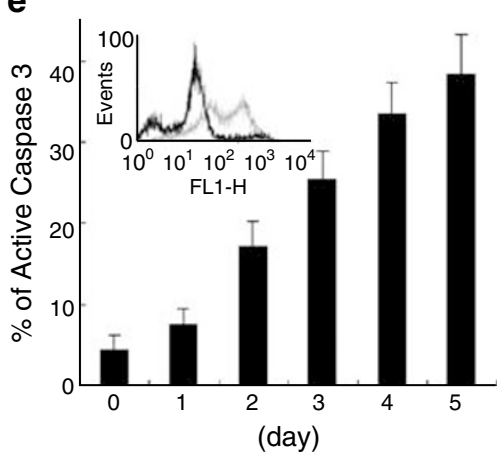

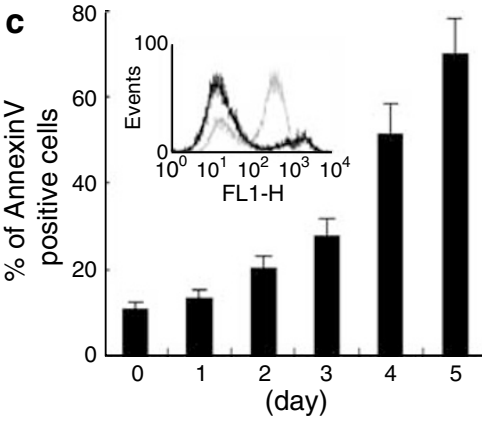

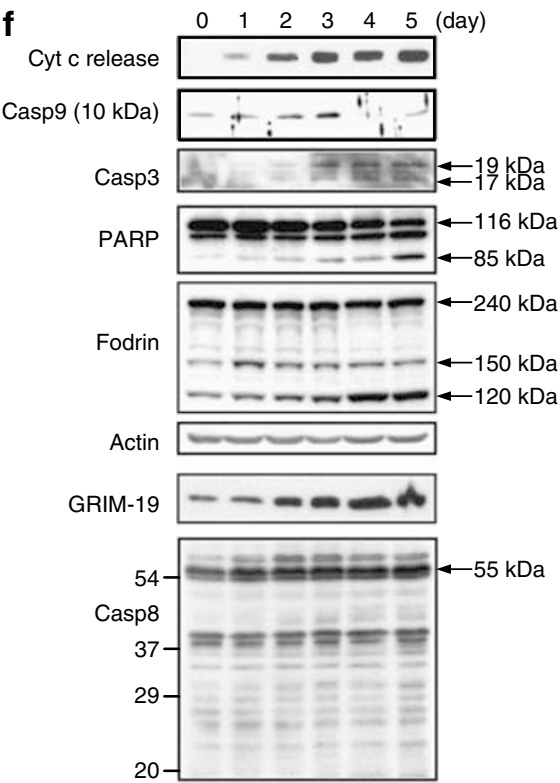

Figure 2 IFN- $\beta$ /RA triggers cell death by activating mitochondrial death pathway. (a) IFN- $\beta /$ RA treatment inhibits cell growth. HeLa cells were treated with different amounts of IFN- $\beta$ and $1 \mu \mathrm{M}$ of RA as indicated for 5 days. Viable cells were then counted as described in Materials and Methods. The numbers represent the mean of five randomly selected fields with standard deviation (S.D.) given as error bars. One of the three independent experiments is shown. (b-e) IFN- $\beta /$ RA treatment causes cell death and loss of mitochondrial membrane potential $\left(\Delta \Psi_{\mathrm{m}}\right)$. HeLa cells were induced with $1500 \mathrm{U} / \mathrm{ml}$ of IFN- $\beta$ and $2 \mu \mathrm{M}$ of RA for different times. Cells were then harvested and cell death was analyzed by PI (b) or Annexin V (c) staining. Positive cells were scored by FACS analysis. The cell numbers represent a mean of three replicates with S.D. as error bars. Mitochondrial potential was tested by TMRE staining and the number of cells with low $\Delta \Psi_{\mathrm{m}}$ is indicated as mean of three replicates (d). Apoptosis was measured by staining the cells with antibody against active caspase-3 (e). In the insets, the black line indicates cells without IFN- $\beta /$ RA treatment and the gray line indicates cells induced by IFN- $\beta$ /RA for 5 days. The $X$-axis represents intensity of the staining, and the $Y$-axis indicates the cell numbers. (f) Analyses of cytochrome $c$ release and caspase activation induced by IFN- $\beta /$ RA. HeLa cells were treated with $1500 \mathrm{U} / \mathrm{ml}$ of IFN- $\beta$ and $2 \mu \mathrm{M}$ of RA, and processed as described in the legend of Figure 1 . Western blot analysis was performed with antibodies as indicated

in the cell numbers $(>80 \%$ ) (Figure $2 \mathrm{a}$ ). Both propidium iodide $(\mathrm{PI})$ (Figure $2 \mathrm{~b}$ ) and Annexin $\mathrm{V}$ (Figure $2 \mathrm{c}$ ) staining showed obvious cell death from day 3 after IFN- $\beta /$ RA treatment, and more than $60 \%$ of total cells undergoing apoptosis at day 5 . Known cell death pathways are mediated by either death receptors or via mitochondria. In the mitochondrial-mediated death pathway, the apoptotic signals lead to opening of the mitochondrial permeability transition pore that induces loss of the transmembrane potential $\left(\Delta \Psi_{\mathrm{m}}\right)$, release of cytochrome $c$, and activation of caspases. ${ }^{19}$ To further explore which apoptotic pathway that IFN- $\beta /$ RA triggers in cells, we checked these apoptotic events. First, we observed that the cell number with low $\Delta \Psi_{\mathrm{m}}$ increased from day 3 , and reached $\sim 50 \%$ at day 5 (Figure 2d). Then, cytochrome $c$ release and caspase activation were analyzed by Western blotting. A very low level of cytochrome $c$ released into the cytoplasm was detected at day 1 , which reached and remained at a high level from days 3 to 5 (Figure 2f). Following cytochrome $c$ release, caspase- 9 was cleaved and activated. A $10-\mathrm{kDa}$ cleaved fragment increased from days 1 to 3 , and further decreased at day 4 , possibly by further cleavage. Activation of caspase- 9 led to cleavage of procaspase-3 and resulted in the release of both $19-\mathrm{kDa}$ and $17-\mathrm{kDa}$ fragments of caspase-3, which were detected from day 2 , and enhanced from days 3 to 5 . Two cellular caspase-3 substrates, poly(ADP-ribose) polymerase (PARP) and $\alpha$-fodrin, were cleaved upon activation of caspase-3, yielding an $85-\mathrm{kDa}$ and a $120-\mathrm{kDa}$ fragment, respectively, from day 2 . These cleaved products further increased from day 2 onwards with very strong expression at day 5 for PARP, and days 4 and 5 for $\alpha$-fodrin. On the other hand, activation of caspase- 8 to 
produce a 23-kDa fragment, stimulated by the death receptor-mediated pathway, was not detectable during the 5-day treatment period (Figure 2f). The activation of caspase- 3 by IFN- $\beta$ /RA was also confirmed by FACS (Figure 2e). Together, our data demonstrate that a mitochondria-initiated death pathway mediates the IFN- $\beta$ / RA-induced cancer cell death.

IFN- $\beta$ /RA does not cause specific cytoplasmic or nuclear translocation of the MRC complex subunits. Apoptosisinducing factor (AIF) is a flavoprotein with $\mathrm{NADH}$ oxidase activity normally residing in the mitochondrial inner membrane space. Upon apoptosis induction, AIF translocates from mitochondria to the cytosol, and subsequently to the nucleus. ${ }^{22}$ We investigated whether GRIM-19 and other MRC subunit proteins also underwent translocation similar to AIF. As shown in Figure 3 (left panels), GRIM-19 and NDUFS5 (complex I subunits), SDHA (a complex II subunit), COX II (a complex IV subunit), ATP1 (a complex $\mathrm{V}$ subunit), and cytochrome $c$ were all located in the mitochondria as observed by colocalization with MitoTracker Red in the untreated cells. After IFN- $\beta /$ RA treatment for 4 days, many cells displayed apoptotic features such as nuclear condensation. Even in these cells, the majority of the proteins tested were still located in the mitochondria, except for cytochrome $c$, which was released into the cytosol (Figure 3, right panels). In the cells with normal nuclear morphology after IFN- $\beta$ /RA treatment for less than 4 days, the complex subunits were all localized inside the mitochondria similar to those in the untreated cells (data not shown). These data indicate the absence of nuclear translocation of MRC complex subunits, including GRIM-19, during IFN/RA-induced cell death.

Knockdown of NDUFS3 and GRIM-19 protects cells against IFN- $\beta$ /RA-induced apoptosis. To further investigate whether MRC is necessary for IFN- $\beta$ /RA-induced apoptosis, we knocked down the complex I subunits, GRIM-19 and NDUFS3, in MCF-7 and HeLa cells using siRNA. Figure $4 a$ shows efficient suppression of GRIM-19 (G19) and NDUFS3 (p30) by their respective siRNAs in comparison with those in the wildtype (WT) cells and the control cells transfected with a scrambled sequence for p30 siRNA (SC). Interestingly, knockdown of GRIM-19 also decreased NDUFS3 expression in HeLa cells, whereas knockdown of NDUFS3 reduced GRIM19 levels in both HeLa and MCF-7 cells. The knockdown

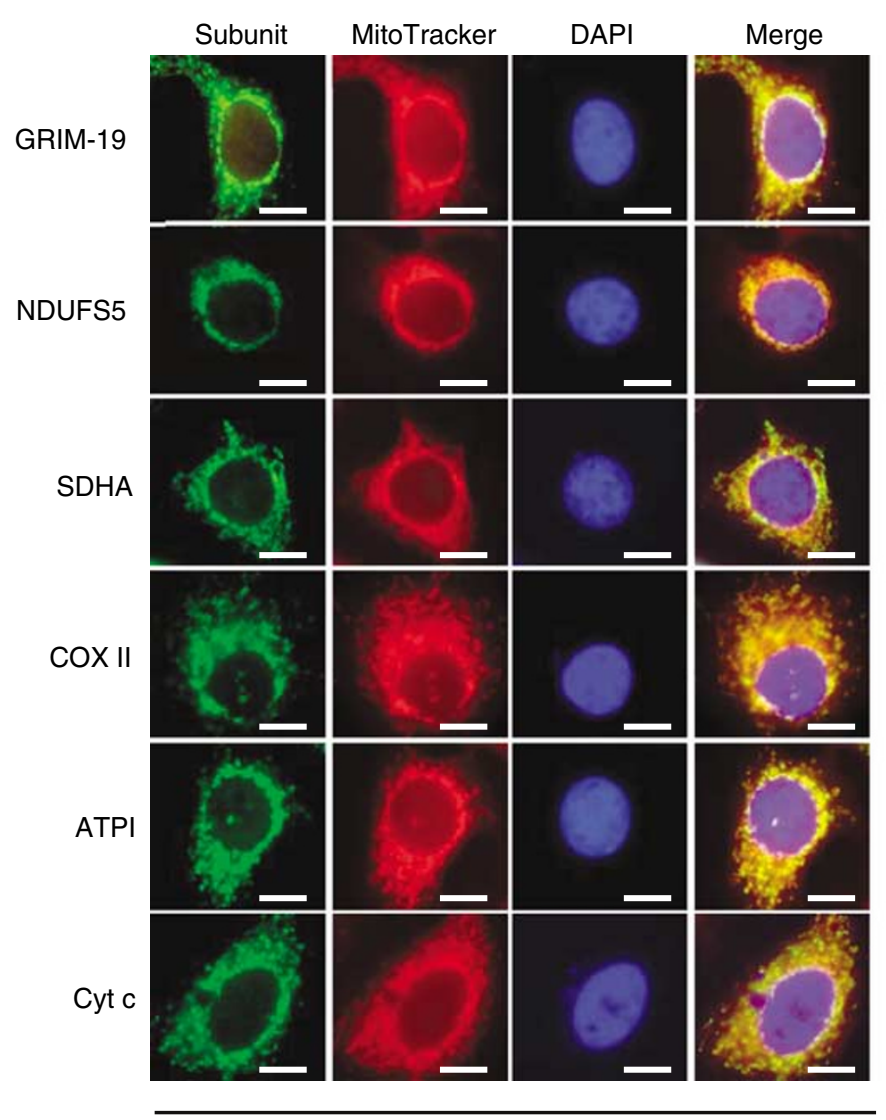

untreated

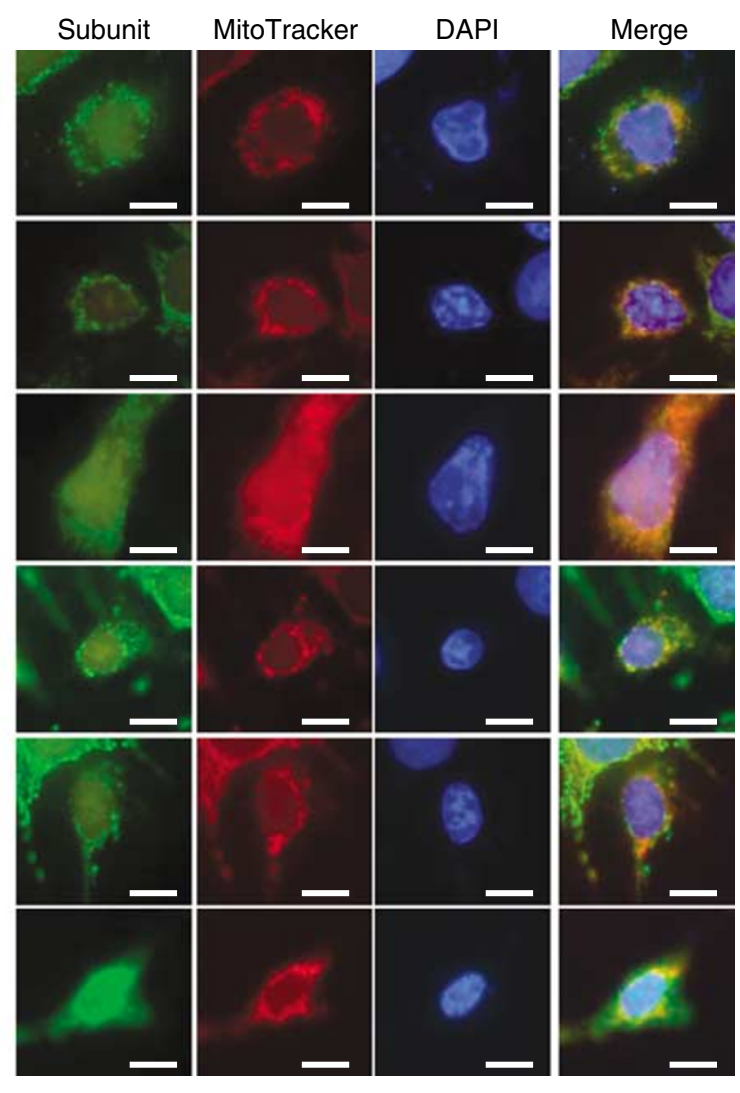

IFN- $\beta /$ RA

Figure 3 Lack of translocation of complex subunits upon stimulation by IFN- $\beta /$ RA. MCF-7 cells were untreated (left panels) or treated with $1000 \mathrm{U} / \mathrm{ml}$ of IFN- $\beta$ and $1 \mu$ M of RA for 4 days (right panels). Cellular localizations of different complex subunits were detected by using primary antibodies (indicated on the left) and FITC-conjugated secondary antibody (green). Mitochondria were detected with MitoTracker Red CMXRos (red) and nuclei with DAPI (blue). The cells were mounted and examined with a fluorescent microscope (Leica DM4000 B). The merged images are shown. Scale bar $=10 \mu \mathrm{m}$ 
a
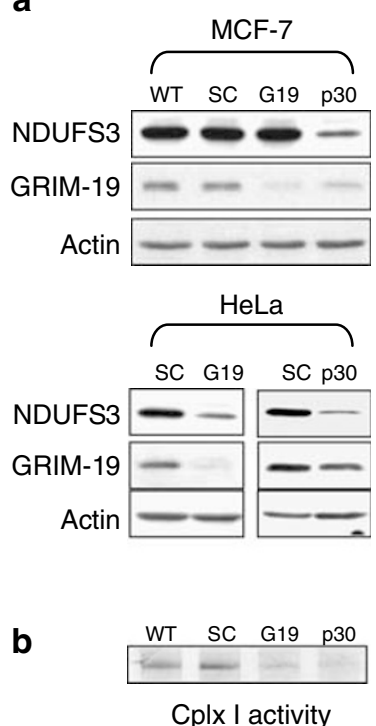

C

Day 0

Day 0

Day 2

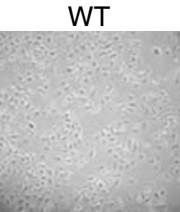

SC

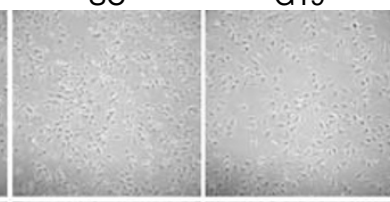

p30

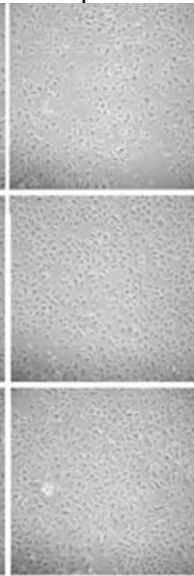

Day 6

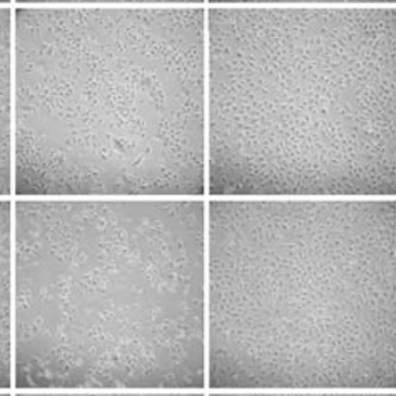

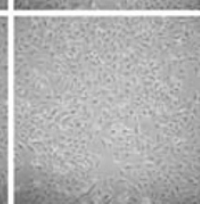

d
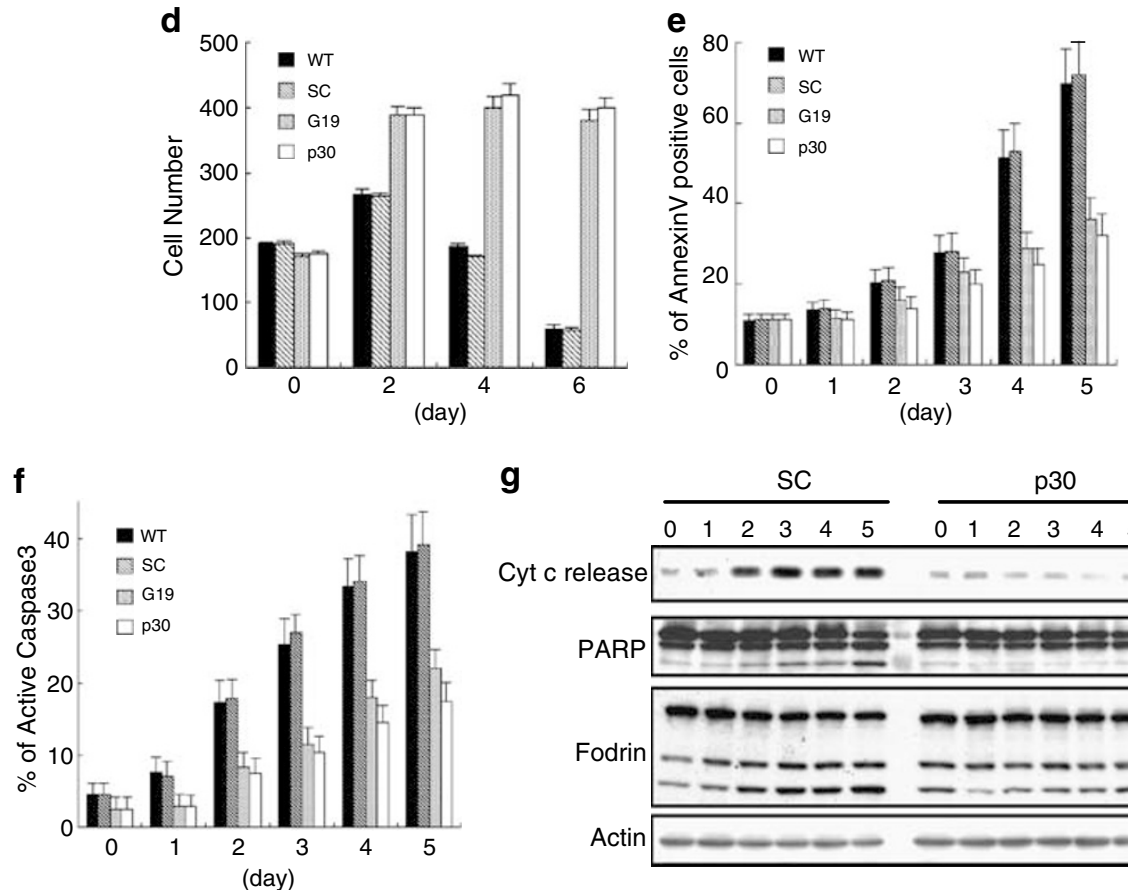

g

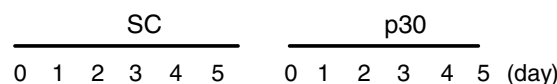

Cyt c release $-\cdots-\infty-\infty-\cdots-\cdots$

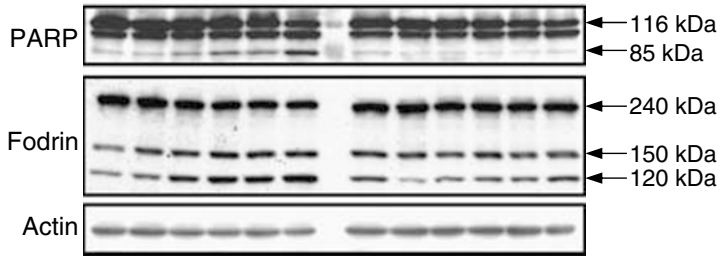

Figure 4 Knockdown of GRIM-19 and NDUFS3 prevents apoptosis induced by IFN- $\beta /$ RA treatment. (a) The efficiency of GRIM-19 and NDUFS 3 knockdown in MCF-7 and HeLa cells was tested by Western blotting with antibodies against GRIM-19 and NDUFS3 in the WT (wild-type), SC (cells transfected with p30 scrambled sequence), G19 (cells transfected with GRIM-19 siRNA), and p30 (cells transfected with NDUFS3 siRNA). (b) Knockdown of GRIM-19 and NDUFS3 impairs complex I activity. The complex I activity was assayed in WT, SC, G19, and p30 cells as described in Materials and Methods. (c) WT, SC, G19, and p30 cells were treated with $1500 \mathrm{U} / \mathrm{ml}$ of IFN- $\beta$ and $2 \mu \mathrm{M}$ of $\mathrm{RA}$, and pictures of the cells were taken by phase contrast photography at days $0,2,4$, and 6 . (d) The cell numbers from five random selected fields were counted, and the means with S.D. are depicted in the graph. Three independent experiments were performed and the results were similar. (e) and (f) WT, SC, G19, and p30 cells were treated as same as in (c) and the cell death was analyzed by staining with Annexin V (e) or active caspase-3 (f) as described in Figure 2. (g) Analyses of cytochrome $c$ release and caspase activation induced by IFN- $\beta /$ RA in SC and p30 cell lines were performed as same as described in Figure $2 f$

efficiency of GRIM-19 and NDUFS3 was further evaluated by their effects on complex I enzymatic activity using a blue native polyacrylamide gel electrophoresis (BN-PAGE) assay. Mitochondria were isolated from cells and the complexes I-V were separated by BN-PAGE. The activity of complex I was analyzed in gel as described previously. ${ }^{14}$ In comparison with the WT and the control SC cells, complex I activity was significantly reduced in $\mathrm{G} 19$ and almost undetectable in p30 cells (Figure 4b). Interestingly, we observed a slow growth after 2 days of treatment and a cell death at days 4 and 6 in the WT 

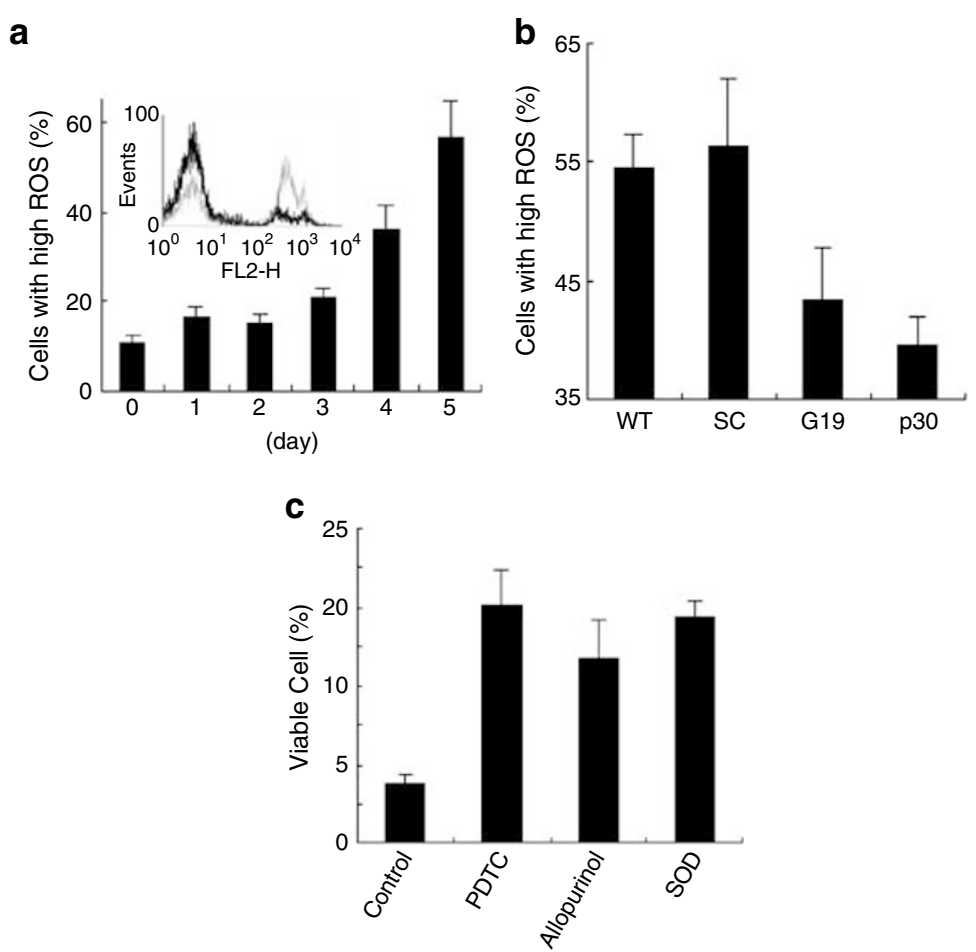

Figure 5 IFN- $\beta /$ RA treatment promotes mitochondrial ROS generation. (a) Time course of ROS generation. MCF- 7 cells were treated with $1500 \mathrm{U} / \mathrm{ml}$ of IFN- $\beta$ and $2 \mu \mathrm{M}$ of RA for different days, and the relative intracellular ROS levels were measured by flow cytometry. The cell numbers are means of three replicates with S.D. In the inset, the black line indicates the cells without IFN- $\beta$ /RA treatment and the gray line refers to cells induced by IFN- $\beta$ /RA for 5 days. (b) Knockdown of GRIM- 19 and NDUFS3 reduces ROS production induced by IFN- $\beta$ /RA. WT, SC, G19, and p30 cells were treated with $1500 \mathrm{U} / \mathrm{ml}$ of IFN- $\beta$ and $2 \mu \mathrm{M}$ of RA for 5 days, and ROS were measured. (c) ROS scavengers partially rescue cell death caused by IFN- $\beta /$ RA. MCF-7 cells were treated with $1000 \mathrm{U} / \mathrm{ml}$ of IFN- $\beta$ and $2 \mu \mathrm{M}$ of RA for 5 days. ROS scavengers were added at day 2. At day 5 , viable cells were counted. The concentrations of different drugs used were $10 \mu \mathrm{M}$ for PDTC, $50 \mathrm{nM}$ for allopurinol, and $10 \mu \mathrm{g} / \mathrm{ml}$ for SOD

and SC cells. However, G19 and p30 cells showed more cell growth after 2 days, which was sustained at days 4 and 6 with much less apoptosis (Figure $4 \mathrm{c}$ and $\mathrm{d}$ ).

The antiapoptotic effect of GRIM-19 and NDUFS3 knockdown was further confirmed. In contrast to WT and SC cells, the death of $\mathrm{G} 19$ and p30 cells was decreased after treatment for 2 days and reduced to $40 \%$ as detected by Annexin $\mathrm{V}$ staining (Figure 4e). Correspondingly, these cells also showed much lower amounts of active caspase-3 (Figure 4f). In agreement with these results, no increases of cytochrome $c$ release and PARP $(85 \mathrm{kDa})$ and $\alpha$-fodrin (120$\mathrm{kDa}$ ) cleavage above the basal level were observed in p30 cells after IFN- $\beta$ /RA treatment for up to 5 days in comparison with control cells (SC) (Figure $4 \mathrm{~g}$ ). Taken together, there results demonstrate that suppression of complex I activity by knocking down GRIM-19 or NDUFS3 subunit confers cell resistance to IFN- $\beta /$ RA-induced apoptosis.

IFN- $\beta$ /RA treatment promotes mitochondrial generation of ROS. It has been documented that electron transport through the MRC is accompanied by the generation of various kinds of free radicals. ${ }^{23,24}$ Overproduction of reactive oxygen species (ROS), the by-product of the MRC, causes cell death. ${ }^{25}$ We examined whether overproduction of ROS by upregulation of MRC results in apoptosis upon treatment with IFN- $\beta /$ RA. As shown in Figure $5 \mathrm{a}$, IFN- $\beta /$ RA treatment led to the cell population with high ROS increased from $10 \%$ in the untreated cells to near $60 \%$ in the cells treated for 5 days. However, G19 and p30 cells had fewer cells with a high ROS production after treatment (Figure $5 b$ ). We next tested whether overproduction of ROS contributed to cell death by using ROS scavengers, pyrrolidinedithiocarbamate (PDTC), allopurinol, and superoxide dismutase (SOD). As these ROS scavengers had nonspecific toxicity to the cells with prolonged incubation and ROS was mainly produced after day 3 , we added these drugs at day 2 after IFN- $\beta$ /RA treatment. As shown in Figure $5 \mathrm{c}$, cell death induced by IFN$\beta /$ RA was partially rescued to different extents by these ROS scavengers. These data suggest that overproduction of ROS by upregulation of MRC activity partially contributes to IFN- $\beta$ / RA-triggered cell death.

Effects of NDUFS3 and GRIM-19 knockdown on IFN- $\beta /$ RA cellular signaling and downstream gene expression. To further reveal the mechanism of the MRC in causing cell death, we next investigated whether the MRC affects the IFN- $\beta /$ RA-triggered signaling pathways and gene expression. IFN-related effects are mainly mediated by the products of interferon-stimulated genes (ISGs). Binding of Type I IFNs to their receptors induces tyrosine phosphorylation of Stat1 and Stat2 by receptor-associated Janus kinases Jak1 and Tyk2. Stat1 and Stat2 form heterodimers and associate with another cytoplasmic protein, $\mathrm{p} 48$, to form a complex named IFN-stimulated gene factor 3 (ISGF3). ISGF3 translocates to 


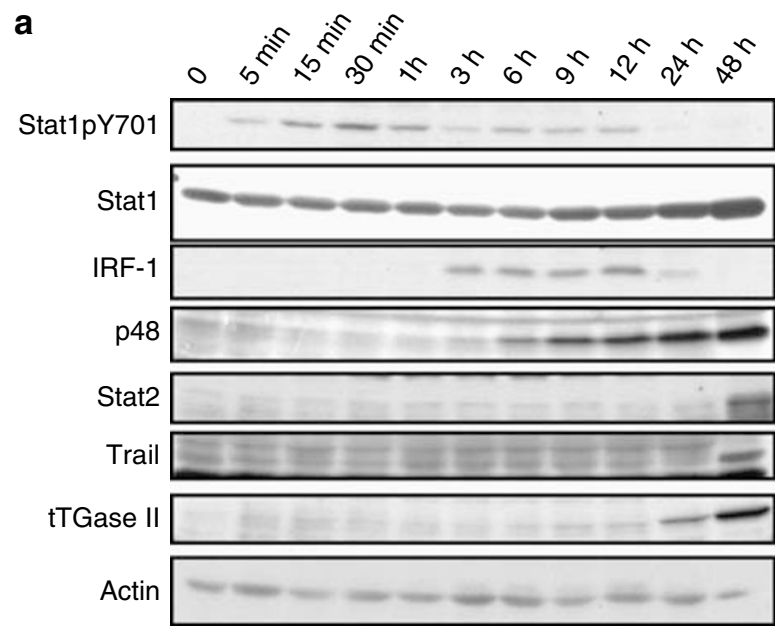

C

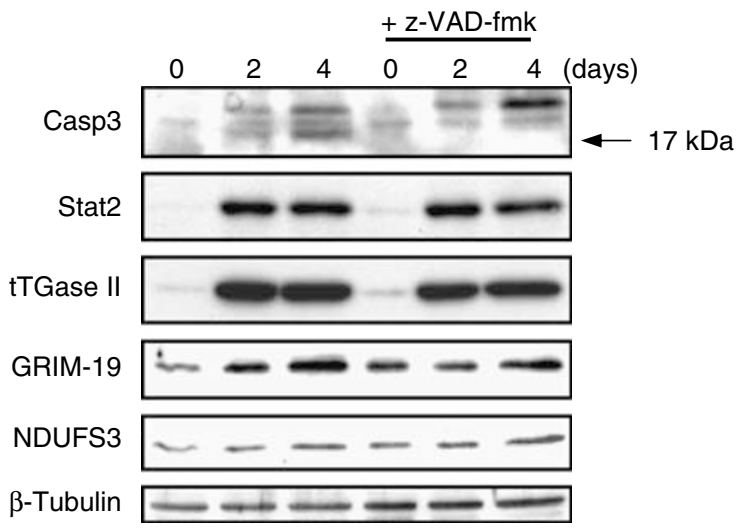

b

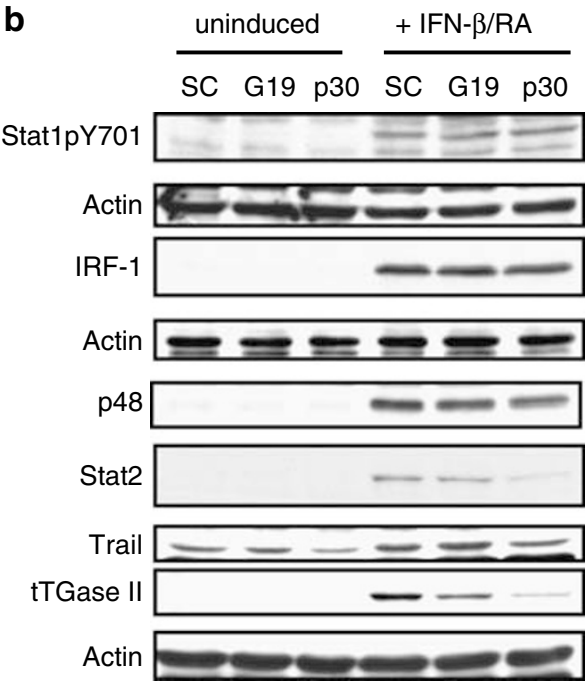

d

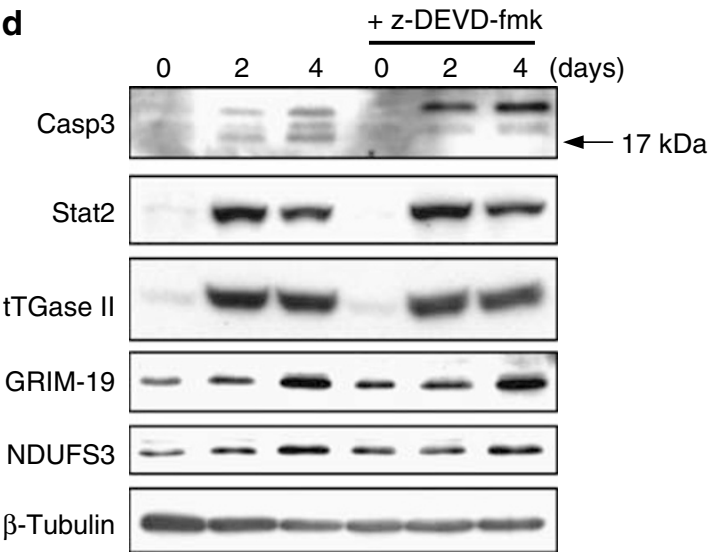

Figure 6 Knockdown of GRIM-19 and NDUFS3 of complex I perturbs late response of IFN- $\beta /$ RA in MCF-7 cells. (a) Protein activation and gene expression profiles in IFN$\beta /$ RA-treated MCF-7 cells. Cells were treated with $1500 \mathrm{U} / \mathrm{ml}$ of IFN- $\beta$ and $2 \mu \mathrm{M}$ of RA and harvested at different time points as indicated. Protein activation and gene expression were analyzed with Western blotting using antibodies as indicated. (b) Knockdown of GRIM-19 or NDUFS3 inhibits late gene expression stimulated by IFN- $\beta /$ RA. SC, G19, and p30 cells were either left uninduced or treated with $1500 \mathrm{U} / \mathrm{ml}$ of IFN- $\beta$ and $2 \mu \mathrm{M}$ of RA for various times ( 30 min for tyrosine phosphorylation of Stat1, $5 \mathrm{~h}$ for IRF1 , and $48 \mathrm{~h}$ for p48, Stat2, tTGase II, and TRAIL). Amounts of proteins were measured by Western blotting using antibodies as indicated. At each time point, actin was probed as loading controls. (c) and (d) Activation of MRC complexes and ISGs by IFN-/RA treatment were not affected by caspase inhibitors. HeLa cells were pretreated with $10 \mu$ M of $z$-VAD-fmk (c) or $5 \mu \mathrm{M}$ of z-DEVD-fmk (d) for $1 \mathrm{~h}$ before being induced with $1500 \mathrm{U} / \mathrm{ml}$ of IFN- $\beta$ and $2 \mu \mathrm{M}$ of RA for 2 or 4 days. Protein activation and gene expression were analyzed with Western blotting using antibodies as indicated. Cells without treatment with caspase inhibitor were used as controls

the nucleus and modulates target gene transcription by binding to regulatory regions called IFN-stimulated response elements (ISRE). ${ }^{26}$ RA was reported to potentiate the effect of IFN by upregulating Stat1, Stat2, and p48. RA itself can also induce expression of some ISGs, such as IRF-1, which can induce expression of more ISGs. ${ }^{27,28}$ IRF-1, as a tumor suppressor with antiproliferative function, can also induce expression of the death ligand TNF-related apoptosisinducing ligand (TRAIL) in cancer cells treated with RA and IFN $-\gamma{ }^{29}$ In addition, both IFN- $\alpha$ and RA are able to increase the expression of tissue transglutaminase II (tTGase II), a multifunctional enzyme with an apoptotic role in various cells. ${ }^{30-32}$ To investigate the IFN- $\beta /$ RA signaling pathway in MCF-7 cells, we tested tyrosine phosphorylation of Stat 1 and gene expression of the key players described above. As shown in Figure 6a, tyrosine phosphorylation of Stat 1 can be detected as early as $5 \mathrm{~min}$ after stimulation, which reached a peak level at $30 \mathrm{~min}$ and decreased after $3 \mathrm{~h}$. The Stat1 protein level was rather constant during the early time course, but increased gradually after treatment from 9 to $48 \mathrm{~h}$. IRF-1 expression was induced from 3 to $12 \mathrm{~h}$, whereas p48 expression increased at $6 \mathrm{~h}$ and was further enhanced at $48 \mathrm{~h}$. In contrast, Stat2 and TRAIL, and tissue tTGase II expression increased at a much later time (48 and $24 \mathrm{~h}$, respectively). These genes, therefore, can be classified as late signaling response genes to the IFN- $\beta /$ RA stimulation.

Next, we examined these responses to the IFN- $\beta /$ RA stimulation in the NDUFS3 (p30) and GRIM-19 (G19) knockdown cells. As shown in Figure 6b, there is no difference in the tyrosine phosphorylation of Stat1 and induction of IRF-1 and p48 among p30, G19, and control SC cells. However, the amounts of Stat2 and tTGase II induced by IFN- $\beta /$ RA in G19 and $p 30$ cells were reduced, which was more significant in p30 than G19 cells. Furthermore, a decrease of TRAIL in p30 


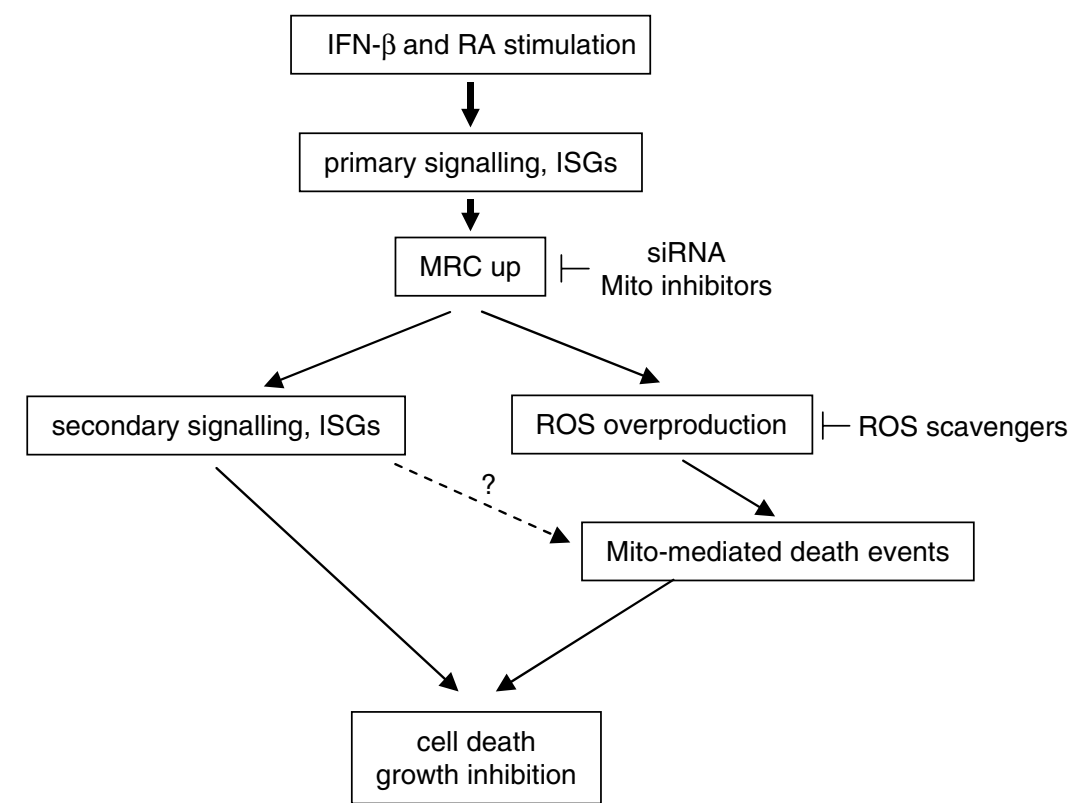

Figure 7 A model of IFN- $\beta$ /RA-induced growth inhibition and cell death

was detected, even in the untreated cells. These results are consistent to the observation of a higher inhibitory efficiency of complex I activity in p30 than G19 cells (Figure 4b). These data suggest that late rather than early responses in the IFN- $\beta /$ RA-induced signaling and gene expression depends on complex I activity.

To exclude the possibility that the late genes are induced as a consequence rather than a cause of apoptosis, we tested protein levels of these genes in response to IFN- $\beta /$ RA in the presence of either a pancaspase inhibitor (z-VAD-fmk) or a caspase-3-specific inhibitor (z-DEVD-fmk). No inducible $\sim 17-\mathrm{kDa}$ cleavage products of caspase-3 were detected when the cells were treated with either Z-VAD-fmk or z-DEVDfmk. Stat2 and tTGasell was still upregulated in the presence of the caspase inhibitors. Furthermore, upregulation of GRIM19 and NDUFS3 by IFN/RA was not inhibited by the caspase inhibitors (Figure $6 \mathrm{c}$ and $6 \mathrm{~d}$ ). These results demonstrate that induction of the MRC proteins and the late gene expression by IFN/RA is not the consequence of cell death.

As IFN- $\beta$ /RA leads to an increase in ROS production, we also explored the possibility that $\mathrm{ROS}$ production was required for the regulation of IFN- $\beta /$ RA-responsive genes. The results showed that pretreatment of the normal cells with ROS scavengers before IFN- $\beta$ /RA did not inhibit Stat 1 tyrosine phosphorylation and the upregulation of IRF-1, p48, Stat2, and tTGase II (Supplementary Figure 1). This experiment suggests that the late signaling induced by IFN- $\beta /$ RA is likely to be independent of ROS production.

The role of the MRC in cell death is specific for IFN- $\beta / R A$ treatment. We also tested the effects of the MRC on cell death induced by generic apoptotic agents. We observed that treatment of HeLa cells with UV irradiation, camptothecin (CPT), or staurosporine (STS) triggered apoptosis by increasing cytochrome $c$ release and cleavage of PARP and $\alpha$-fodrin in both control SC and the GRIM-19 or NDUFS3 knockdown cells. Consistently, the expression levels of GRIM-19 and NDUFS3 were not elevated by these treatments (Supplementary Figure $2 \mathrm{a}-\mathrm{c}$ ). Furthermore, cell death indicated by cell morphology, Annexin $V$ staining, and $\Delta \Psi_{\mathrm{m}}$ induced by these agents was similar regardless of whether or not GRIM-19 and NDUFS3 were knocked down (Supplementary Figure 2d-f). These results indicate a specific involvement of the MRC in IFN- $\beta /$ RA-induced cell death.

A model of IFN- $\beta /$ RA-induced cell death. IFN- $\beta /$ RAinduced apoptosis is a prolonged process that involves complex regulatory events. Based on our data presented above, we propose a model for IFN- $\beta /$ RA-induced cell death with a central role for the MRC (Figure 7). IFN- $\beta$ /RA stimulation induces activation of signal molecules and primary gene expression. These early responses promote MRC activity by upregulation of its complexes. Increased MRC activity, in turn, promotes more ROS production, which triggers mitochondrial-mediated apoptosis pathways. In parallel, MRC activation amplifies IFN- $\beta /$ RA-induced signaling by upregulating expression of late response genes, either antiproliferative or proapoptotic, which also leads to cell growth inhibition and apoptosis.

\section{Discussion}

A synergistic anticancer action by combination of RA with IFNs is extensively analyzed both in vitro and in clinical trials. $^{8,9}$ The discovery of GRIM-19 as an IFN- $\beta /$ RA-inducible gene product ${ }^{10}$ and a mitochondrial complex I subunit ${ }^{11,14}$ has led us to further explore the possible link between the MRC and IFN- $\beta /$ RA-inducible cell growth inhibition and cell death. In this study, we have provided several lines of evidence to demonstrate an essential role of the MRC in IFN- $\beta /$ RAinduced signaling and cell death. However, interestingly, the 
role of MRC in cell death seems specific only for the combination of IFN- $\beta$ and RA, as IFN or RA alone did not induce either upregulation of the MRC subunits or the cell death (Figures 1 and 2). Furthermore, other death stimuli such as UV, CPT, and staurosporine caused cell death without inducing the expression of GRIM-19 and NDUFS3, and knockdown of these two genes did not prevent cell death induced by these generic death agents (Supplementary Figure 2). Therefore, MRC plays a specific role in IFN- $\beta / R A$ inducible cancer cell death.

The mechanism of how upregulation of the MRC leads to cell death is not fully understood. We have provided evidence that overproduction of ROS and upregulation of late gene expression necessary for cell death may be two major reasons. It has been reported that the transcription factor nuclear factor- $\kappa \mathrm{B}$ (NF- $\kappa \mathrm{B})$ can be upregulated in response to various oxidative stress stimuli. ${ }^{33}$ However, inhibition of ROS generation did not suppress the upregulation of the IFN- $\beta /$ RAresponsive genes (Supplementary Figure 1). Therefore, it is unlikely that IFN- $\beta /$ RA triggers gene expression via ROS production. Other mechanisms such as nuclear translocation were also investigated. GRIM-19 was originally claimed as a nuclear protein, ${ }^{10}$ but was later shown to be a mitochondrial protein. ${ }^{11,12,14}$ In a recent review by Kalvakolanu, ${ }^{34}$ it was proposed that GRIM-19 may initiate apoptosis, like cytochrome $c$ and AIF, by translocation from the mitochondria to the nucleus upon IFN- $\beta /$ RA stimulation. To test this hypothesis, we analyzed the cellular localization of GRIM-19, as well as other MRC subunit proteins, in the absence and presence of IFN- $\beta /$ RA. We showed that without induction, these proteins colocalized with MitoTracker Red and displayed a typical mitochondrial localization pattern. IFN- $\beta /$ RA treatment resulted in varying levels of apoptosis. However, nuclear translocation of GRIM-19 or other MRC subunits tested was not found in both nonapoptotic and apoptotic cells. As a control, cytochrome $c$ was translocated into the cytoplasm after treatment (Figure 3). These results demonstrate that the MRC does not exert its regulatory role in IFN- $\beta$ / RA-induced cell death via direct nuclear translocation. Our data also show that the regulation and function of GRIM-19 are very similar to NDUFS3, another complex I subunit. This supports that GRIM-19 is a subunit of the MRC complex I, but not a nuclear protein with a nuclear function in IFN- $\beta$ /RAtriggered cancer cell death. Our data therefore clarify the confusion in the field about the identity and cellular localization of GRIM-19.

The function of the MRC complex I activity in protecting cells against IFN- $\beta /$ RA-induced apoptosis is demonstrated by knockdown of GRIM-19 and NDUFS3 in MCF-7 and HeLa cells (Figures 4-6). The effects of the other MRC complexes were also investigated by using the inhibitors rotenone, 2thenoyltrifluoroacetone (TTFA), antimycin A, and oligomycin, for inhibition of complexes I, II, III, and V, respectively. As prolonged inhibition by these drugs at the optimal doses that completely inhibits complex activity killed cells even in the absence of IFN- $\beta /$ RA, suboptimal doses of each inhibitor that did not cause cell death were used. Although rotenone, TTFA, and oligomycin exhibited partial rescue for IFN- $\beta /$ RA-induced cell death, the inhibitory effects of these drugs at the suboptimal doses used in these experiments on complex activities remains unknown (data not shown). Therefore, a clear conclusion for this could not be drawn currently.

Mitochondria have both life-supporting functions and deathpromoting activities. However, studies attempting to address the question of whether these two crucial cellular processes are linked to each other have resulted in controversial conclusions. ${ }^{15}$ Early evidence showed that cultured cells lacking mitochondrial DNA and therefore deficient in respiration could undergo apoptosis, suggesting that MRC is not necessary for apoptosis. ${ }^{35,36}$ Recent evidence, however, also indicates that the physiological functions of mitochondria are involved in cell death. ${ }^{15}$ As examples, reports show that a functional electron transport chain regulates oxygen deprivation-induced cell death, and an ATP synthase is required in TNF-induced apoptosis. ${ }^{37-39}$ In this study, using a lossof-function approach, we demonstrated that the function of complex I is necessary for IFN/RA-induced cancer cell death, suggesting that changes in cellular metabolism can directly affect the sensitivity of a cell to apoptosis induced by specific agents. Our data provide another example where mitochondrial physiology plays a direct role in apoptotic cell death.

\section{Materials and Methods}

Cell culture, chemicals, and reagents. HeLa cells were maintained in Eagle's minimum essential medium (MEM) (Sigma, St Louis, IL, USA) supplemented with $10 \%$ fetal bovine serum (FBS). When HeLa were treated with INF- $\beta$ and RA, $5 \%$ charcoal-stripped FBS was used. MCF- 7 cells were maintained in RPMI-1640 medium (Sigma) supplemented with 10\% FBS. During treatment with IFN- $\beta$ and RA, MCF-7 cells were cultured in phenol red-free MEM (Sigma) supplemented with $5 \%$ charcoal-stripped FBS and $10^{-11} \mathrm{M}$ estradiol. RA, PI, PDTC, allopurinol, and SOD were purchased from Sigma. TMRE, dihydroethidium (2-HE) and MitoTracker Red CMXRos were from Molecular Probes (Eugene, OR, USA). z-DEVD-fmk and z-VAD-fmk were purchased from Santa Cruz Biotechnology Inc. (Santa Cruz, CA, USA) and Calbiochem (Darmstadt, Germany), respectively. Antibodies against NDUFS5, NDUFB6, NDUFS3, NDUFA9, SDHA, UQCRFS1, COX II, COX IV, and ATPI were from Molecular Probes. $\beta$-Tubulin, active caspase9, p48, TRAIL, and tTGase II antibodies were from Santa Cruz Biotechnology. Antiactin antibody was from Sigma. IRF-1 and Stat2 antibodies were from BD Transduction Laboratories (Lexington, KY, USA). Cytochrome $c$, caspase-8, and PARP antibodies were from BD Pharmingen (San Diego, CA, USA). Antibody against $\alpha$-fodrin was from Chemicon (Temecula, CA, USA). Stat1-pY701 antibody was from Cell Signalling (Danvers, MA, USA). GRIM-19 antibody was made as described. $^{14}$

Western blot analysis. Cells were harvested and washed with cold phosphate-buffered saline (PBS) and lysed in RIPA buffer $(150 \mathrm{mM} \mathrm{NaCl}, 50 \mathrm{mM}$ Tris- $\mathrm{HCl}, \mathrm{pH} 7.2,1 \%$ deoxycholic acid, 1\% Triton X-100, 0.1\% sodium dodecyl sulfate (SDS), $0.25 \mathrm{mM}$ EDTA) with the protease inhibitor cocktail (Roche, Basel, Switzerland). The lysate was separated by SDS-polyacrylamide gel electrophoresis (SDS-PAGE) after being boiled in Laemmli buffer, and transferred to polyvinylidene difluoride (PVDF) membrane. The membrane was blocked with PBS containing $0.1 \%$ Tween 20 and $1 \%$ bovine serum albumin before it was incubated with the appropriate primary and secondary antibodies. The bound antibodies were visualized by enhanced chemiluminescene (Amersham Bioscience, UK).

Cell growth assay. Cells were seeded in $60 \mathrm{~mm}$ dish at $2.6 \times 10^{5}$ per dish and allowed to grow for $24 \mathrm{~h}$ before stimulation by IFN- $\beta /$ RA for various times. Cells were washed with PBS and fixed with $70 \%$ ethanol at $4{ }^{\circ} \mathrm{C}$ for at least $1 \mathrm{~h}$ and stained with 4',6-diamidino-2-phenylindole (DAPI). Pictures were taken at randomly selected fields under a fluorescence microscope. Healthy cells were counted from each field and an average of five fields was taken as viable cell number. As a control, one plate was fixed before stimulation, and cell number obtained from this plate was taken as $0 \%$ growth. The cell number obtained from a plate of untreated cells at the end of the experiment was subtracted by the cell number at $0 \%$ growth and this was referred to as $100 \%$ growth. Cell number from the plate treated with 
IFN- $\beta$ /RA was counted in a similar manner and the percentage of growth was plotted with reference to the untreated control. Each experiment was repeated at least three times and the results were comparable.

Measurement of $\Delta \Psi_{m}, R O S$ and apoptosis. Cells were treated as indicated, harvested and washed in PBS. For assessment of $\Delta \Psi_{\mathrm{m}}$ and ROS, cells were resuspended in buffer $\mathrm{A}(20 \mathrm{mM}$ Hepes-KOH, $\mathrm{pH} 7.5,10 \mathrm{mM} \mathrm{KCl}, 1.5 \mathrm{mM}$ $\mathrm{MgCl}_{2}, 1 \mathrm{mM}$ sodium EGTA, $1 \mathrm{mM}$ dithiothreitol and $250 \mathrm{mM}$ sucrose) and incubated with $50 \mathrm{nM}$ of TMRE for $\Delta \Psi_{\mathrm{m}}$ and $2 \mu \mathrm{M}$ of 2-HE for ROS for $30 \mathrm{~min}$ at $37^{\circ} \mathrm{C}$ in the dark. For cell death analysis, cells were washed and resuspended in PBS after treatment. PI $(0.5 \mu \mathrm{g} / \mathrm{ml})$ was then added. Assays were performed by flow cytometry. A commercial kit for Annexin V staining from BD Pharmingen was also used for death assay. Annexin V was measured in FL-1 (green), TMRE and 2-HE in FL-2 (red), and PI in FL-3 (far red).

Cytochrome $c$ release assay. It was performed with a single-step protocol as described previously. ${ }^{40}$ Briefly, HeLa cells were lysed for 15 min on ice in a solution consisting of $20 \mathrm{mM}$ Hepes, pH 7.2, $50 \mathrm{mM} \mathrm{KCl}, 5 \mathrm{mM} \mathrm{MgCl} 2,1 \mathrm{mM}$ EDTA, $1 \mathrm{mM}$ EGTA, $250 \mathrm{mM}$ sucrose, $0.025 \%$ digitonin, and protease inhibitor cocktail (Roche). After removal of the cell debris by centrifugation at 13200 r.p.m. for $10 \mathrm{~min}$ at $4^{\circ} \mathrm{C}, 10 \mu \mathrm{g}$ of cell lysate was subjected to Western blot analysis using an antibody against cytochrome $c$.

Immunostaining. MCF-7 cells grown on glass coverslips in culture medium were first treated with $500 \mathrm{nM}$ of MitoTracker Red CMXRos for $45 \mathrm{~min}$ before being fixed in $3.7 \%$ formaldehyde in PBS, permeabilized with $0.2 \%$ Triton X-100 in PBS, and blocked with FDB (5\% normal goat serum, $2 \% \mathrm{FBS}$, and $2 \%$ bovine serum albumin in PBS). The cellular localization of complex subunits was detected using the respective primary monoclonal antibodies and an anti-mouse secondary antibody conjugated to fluorescein isothiocyanate (FITC). The cells were mounted in GEL MOUNT ${ }^{\mathrm{TM}}$ (Biomeda Corp., Foster City, CA, USA) and examined under a fluorescent microscope (Leica DM4000 B Wetzlar, Germany). Images were collected and processed with a Leica DFC300 FX camera and Leica FW4000 software.

siRNA. Knockdowns by siRNA were performed using PSUPER.neo (OligoEngine, Seattle, WA, USA) following the manufacturer's instructions. The following sequences were used: GRIM-19, $5^{\prime}$-GGCACTGGAGCATAATGAA-3'; NDUFS3, 5'-TGTGGATCCTAGACAGCGC-3'; and scrambled NDUFS3, 5'GCG CGATCCTAGACATGTG- $3^{\prime}$. The plasmids were then transfected into MCF-7 and HeLa cells by Lipofectamine 2000 (Invitrogen, Carlsbad, CA, USA). Monoclonal stable cell lines were established. For each protein, four efficiently knockdown clones were pooled and used for further experiments.

Mitochondrial complex I OXPHOS assays. Mitochondria were isolated according to a protocol as described previously. ${ }^{14}$ Mitochondrial proteins were solubilized in $40 \mu \mathrm{l}$ of solution containing $750 \mathrm{mM}$ 6-aminocarproic acid, $50 \mathrm{mM}$ Bistris ( $\mathrm{pH} 7.0$ ), and $5 \mu \mathrm{l}$ of $10 \%$ dodecylmaltoside. The lysate was centrifuged and the supernatant was used for further assays. The separation of mitochondrial complexes was performed on 5-18\% polyacrylamide gradient BN-PAGE. In-gel colorimetric reaction for OXPHOS of complex I was performed on the BN-PAGE as described previously. ${ }^{14}$ Briefly, following BN-PAGE, the gels were rinsed with distilled water and then equilibrated in complex I reaction buffer $(0.1 \mathrm{M} \mathrm{Tris}-\mathrm{HCl}, \mathrm{pH}$ 7.4) for $10 \mathrm{~min}$. The gels were subsequently incubated for $30 \mathrm{~min}$ in fresh complex I reaction buffer containing $0.2 \mathrm{mM} \mathrm{NADH}$ and $0.2 \%$ nitroblue tetrazolium (NBT) as substrates. The gels were then destained overnight in $45 \%$ methanol and $10 \%$ acetic acid.

Quantitative RT-PCR. RNA was isolated by TRIzol reagent (Invitrogen). Firststrand synthesis was carried out using a poly(dT) primer and Superscript II Reverse Transcriptase (Invitrogen). Real-time PCR was performed on a Roche Light Cycler using the Light Cycler FastStart DNA master SYBR Green I kit (Roche). Quantification was carried out by normalizing levels to the amount of total cDNA using the ubiquitously expressed GAPDH as a standard. The primers used are $5^{\prime}$ ATGGGCCCATCGACTACAAAC-3' (forward) and $5^{\prime}$-GAAGCCGTGGCT GGCA TGGA-3' (reverse) for GRIM-19; $5^{\prime}$-CACGCGCCCCACTGTCA-3' (forward) and $5^{\prime}$ CACCCGCTTCACTTCATCATCATA-3' (reverse) for NDUFS3; and 5'-TCCATCA CCATCTTCCAG - $3^{\prime}$ (forward) and 5'-ATGAGTCCTTCCACGATACC-3' (reverse) for GAPDH.
Flow cytometric analysis of caspase-3 activation. Upon induction of apoptosis, caspase-3 undergoes conformational changes that exposes otherwise inaccessible epitopes. By staining the cells with antiactivated caspase-3 (Cell Signaling) and an FITC-conjugated secondary antibody, increases in accessibility of the epitopes can be monitored by flow cytometry. At specific time points following IFN- $\beta /$ RA treatment, the cells were harvested, fixed with $2 \%$ formaldehyde, and permeabilized with ice-cold $90 \%$ methanol. After staining with primary and secondary antibodies, cells were analyzed by flow cytometer in FL-1 (green).

Acknowledgements. We thank I Masafumi for providing IFN- $\beta$, and A Porter and CP Lim for critical reading of the manuscript. This work was supported by the Agency for Science, Technology, and Research of Singapore. X Cao is an adjunct staff in Department of Biochemistry, National University of Singapore.

1. Decker T, Muller M, Stockinger S. The yin and yang of type I interferon activity in bacterial infection. Nat Rev Immunol 2005; 5: 675-687.

2. Belardelli F, Ferrantini $M$, Proietti $E$, Kirkwood JM. Interferon-alpha in tumor immunity and immunotherapy. Cytokine Growth Factor Rev 2002; 13: 119-134.

3. Stark GR, Kerr IM, Williams BR, Silverman RH, Schreiber RD. How cells respond to interferons. Annu Rev Biochem 1998; 67: 227-264.

4. Laudet V, Gronemeyer H. The Nuclear Receptor Facts Book. Academic Press: San Diego, 2002.

5. Love JM, Gudas LJ. Vitamin A, differentiation and cancer. Curr Opin Cell Biol 1994; 6: 825-831.

6. Melnick A, Licht JD. Deconstructing a disease: RARalpha, its fusion partners, and their roles in the pathogenesis of acute promyelocytic leukemia. Blood 1999; 93: 3167-3215.

7. Altucci $\mathrm{L}$, Gronemeyer $\mathrm{H}$. The promise of retinoids to fight against cancer. Nat Rev Cancer 2001; 1: 181-193.

8. Lippman SM, Lotan R, Schleuniger U. Retinoid-interferon therapy of solid tumors. Int $J$ Cancer 1997; 70: 481-483.

9. Ortiz MA, Bayon Y, Lopez-Hernandez FJ, Piedrafita FJ. Retinoids in combination therapies for the treatment of cancer: mechanisms and perspectives. Drug Resist Update 2002; $\mathbf{5}$ : $162-175$.

10. Angell JE, Lindner DJ, Shapiro PS, Hofmann ER, Kalvakolanu DV. Identification of GRIM19 , a novel cell death-regulatory gene induced by the interferon-beta and retinoic acid combination, using a genetic approach. J Biol Chem 2000; 275: 33416-33426.

11. Fearnley IM, Carroll J, Shannon RJ, Runswick MJ, Walker JE, Hirst J. GRIM-19, a cell death regulatory gene product, is a subunit of bovine mitochondrial NADH:ubiquinone oxidoreductase (complex I). J Biol Chem 2001; 276: 38345-38348.

12. Lufei C, Ma J, Huang G, Zhang T, Novotny-Diermayr V, Ong CT et al. GRIM-19, a deathregulatory gene product, suppresses Stat3 activity via functional interaction. EMBO J2003; 22: $1325-1335$.

13. Zhang J, Yang J, Roy SK, Tininini S, Hu J, Bromberg JF et al. The cell death regulator GRIM-19 is an inhibitor of signal transducer and activator of transcription 3. Proc Natl Acad Sci USA 2003; 100: 9342-9347.

14. Huang G, Lu H, Hao A, Ng DC, Ponniah S, Guo K et al. GRIM-19, a cell death regulatory protein, is essential for assembly and function of mitochondrial complex I. Mol Cell Biol 2004; 24: 8447-8456.

15. Newmeyer DD, Ferguson-Miller S. Mitochondria: releasing power for life and unleashing the machineries of death. Cell 2003; 112: 481-490.

16. Saraste M. Oxidative phosphorylation at the fin de siecle. Science 1999; 283: 1488-1493.

17. Coenen MJ, van den Heuvel LP, Smeitink JA. Mitochondrial oxidative phosphorylation system assembly in man: recent achievements. Curr Opin Neurol 2001; 14: 777-781.

18. Hatefi $Y$. The mitochondrial electron transport and oxidative phosphorylation system. Annu Rev Biochem 1985; 54: 1015-1069.

19. Lawen A. Apoptosis - an introduction. Bioessays 2003; 25: 888-896.

20. Hirst J, Carroll J, Fearnley IM, Shannon RJ, Walker JE. The nuclear encoded subunits of complex I from bovine heart mitochondria. Biochim Biophys Acta 2003; 1604: 135-150.

21. Schagger $\mathrm{H}$, Pfeiffer $\mathrm{K}$. Supercomplexes in the respiratory chains of yeast and mammalian mitochondria. EMBO J 2000; 19: 1777-1783

22. Susin SA, Lorenzo HK, Zamzami N, Marzo I, Snow BE, Brothers GM et al. Molecular characterization of mitochondrial apoptosis-inducing factor. Nature 1999; 397: 441-446.

23. Green DR, Reed JC. Mitochondria and apoptosis. Science 1998; 281: 1309-1312.

24. Tan S, Sagara $Y$, Liu $Y$, Maher $P$, Schubert $D$. The regulation of reactive oxygen species production during programmed cell death. J Cell Biol 1998; 141: 1423-1432.

25. Mattson MP, Kroemer G. Mitochondria in cell death: novel targets for neuroprotection and cardioprotection. Trends Mol Med 2003; 9: 196-205.

26. Darnell Jr JE, Kerr IM, Stark GR. Jak-STAT pathways and transcriptional activation in response to IFNs and other extracellular signaling proteins. Science 1994; 264 $1415-1421$.

27. Fujita T, Kimura $Y$, Miyamoto M, Barsoumian EL, Taniguchi T. Induction of endogenous IFN-alpha and IFN-beta genes by a regulatory transcription factor, IRF-1. Nature 1989; 337: 270-272. 
28. Taniguchi T, Takaoka A. A weak signal for strong responses: interferon-alpha/beta revisited. Nat Rev Mol Cell Biol 2001; 2: 378-386.

29. Clarke N, Jimenez-Lara AM, Voltz E, Gronemeyer H. Tumor suppressor IRF-1 mediates retinoid and interferon anticancer signaling to death ligand TRAIL. EMBO J 2004; 23 : 3051-3060.

30. Lorand L, Graham RM. Transglutaminases: crosslinking enzymes with pleiotropic functions. Nat Rev Mol Cell Biol 2003; 4: 140-156.

31. Melino G, Annicchiarico-Petruzzelli M, Piredda L, Candi E, Gentile V, Davies PJ et al. Tissue transglutaminase and apoptosis: sense and antisense transfection studies with human neuroblastoma cells. Mol Cell Biol 1994; 14: 6584-6596.

32. Giandomenico V, Lancillotti F, Fiorucci G, Percario ZA, Rivabene R, Malorni W et al. Retinoic acid and IFN inhibition of cell proliferation is associated with apoptosis in squamous carcinoma cell lines: role of IRF-1 and TGase II-dependent pathways. Cell Growth Differ 1997; 8: 91-100.

33. Imbert V, Rupec RA, Livolsi A, Pahl HL, Traenckner EB, Mueller-Dieckmann C et al. Tyrosine phosphorylation of I kappa B-alpha activates NF-kappa B without proteolytic degradation of I kappa B-alpha. Cell 1996; 86: 787-798.
34. Kalvakolanu DV. The GRIMs: a new interface between cell death regulation and interferon/ retinoid induced growth suppression. Cytokine Growth Factor Rev 2004; 15: 169-194.

35. Jacobson MD, Burne JF, King MP, Miyashita T, Reed JC, Raff MC. Bcl-2 blocks apoptosis in cells lacking mitochondrial DNA. Nature 1993; 361: 365-369.

36. Marchetti P, Susin SA, Decaudin D, Gamen S, Castedo M, Hirsch T et al. Apoptosisassociated derangement of mitochondrial function in cells lacking mitochondrial DNA. Cancer Res 1996; 56: 2033-2038.

37. Chandra D, Liu JW, Tang DG. Early mitochondrial activation and cytochrome $c$ upregulation during apoptosis. J Biol Chem 2002; 277: 50842-50854.

38. McClintock DS, Santore MT, Lee VY, Brunelle J, Budinger GR, Zong WX et al. Bcl-2 family members and functional electron transport chain regulate oxygen deprivation-induced cell death. Mol Cell Biol 2002; 22: 94-104.

39. Shchepina LA, Pletjushkina OY, Avetisyan AV, Bakeeva LE, Fetisova EK, Izyumov DS et al. Oligomycin, inhibitor of the F0 part of $\mathrm{H}^{+}$-ATP-synthase, suppresses the TNF-induced apoptosis. Oncogene 2002; 21: 8149-8157.

40. Yakovlev AG, Di Giovanni S, Wang G, Liu W, Stoica B, Faden Al. BOK and NOXA are essential mediators of p53-dependent apoptosis. J Biol Chem 2004; 279: 28367-28374.

Supplementary Information accompanies the paper on Cell Death and Differentiation website (http://www.nature.com/cdd) 